\title{
How Eric Martell Cooked up a 'Digital Food Court'
}

\author{
Jon Eckhardt (University of Wisconsin-Madison)
}

KEYWORDS: Innovation, Restaurants, student entrepreneurs, Videos, Student innovators.

Eric Martell co-founded EatStreet as a 19-year-old to create a "digital food court" and online ordering for momand-pop restaurants serving hungry college students. His startup has now grown to 110 cities, with 50 full time employees and more than 10,000 restaurant clients. In some college towns, half of the student body use EatStreet regularly. Martell talked with EIX editor Jon Eckhardt about how a food delivery man sparked the idea for EatStreet, his company's approach to problemsolving, and his make-or-break moments -- including turning down high-paying jobs for the uncertain life of an entrepreneur.

Additional Search Terms: restaurant industry, delivery services, Uber, Uber Eats, customer service, gig economy 